Check for updates

Cite this: RSC Adv., 2019, 9, 39572

Received 1st October 2019

Accepted 11th November 2019

DOI: $10.1039 / c 9 r a 07966 a$

rsc.li/rsc-advances

\section{The cotreatment of landfill leachate and high- nitrate wastewater using SBRs: evaluation of denitrification performance and microbial analysis $\uparrow$}

\author{
Huaguang Liu, (D) ${ }^{a}$ Xingyu Zhou, (D)*bc Chaoshen Zhang ${ }^{a}$ and Jinsong Zhang ${ }^{\text {abc }}$
}

Resourceful disposal of landfill leachate has always been an intractable worldwide problem. This study was conducted to investigate the feasibility of biologically treating a combined waste stream of landfill leachate and high-concentration nitrate nitrogen (high-nitrate) wastewater. Raw landfill leachate was pretreated using anaerobic fermentation and ammonia stripping to improve biodegradability. The control sequencing batch reactor (SBR, named RO) was fed only with synthetic high-nitrate wastewater with sodium acetate as the carbon source, whereas the other experimental SBR (named R1) was loaded with mixtures containing leachates. Excessive increase in leachate adversely affected the cotreatment, and it was concluded that the landfill leachate volume ratio should never exceed $7.5 \%$ of the total wastewater (14\% of the initial COD) based on further batch experiments. The maximum specific denitrification rate of $58.05 \mathrm{mg} \mathrm{NO}_{3}{ }^{-}-\mathrm{N}$ (gVSS h) ${ }^{-1}$ was attained in R1, while that of $32.32 \mathrm{mg} \mathrm{NO}_{3}^{-}-\mathrm{N}(\mathrm{gVSS} \mathrm{h})^{-1}$ was obtained in RO. Illumina MiSeq sequencing revealed that adding landfill leachate did not change the fact that Pseudomonas, Thauera, and Pannonibacter dominant in the sodium acetate supported the denitrification systems, but led to the adjustment of their relative abundance. Moreover, the narG, nirk, nirS, and norB denitrifying genes exhibited increased abundance by $138-980 \%$ in the cotreated system, which was confirmed by $q-P C R$ analyses. These findings reveal that the denitrification efficiency of activated sludge in SBR cotreated with landfill leachate and high-nitrate wastewater significantly improved, and this may contribute toward the understanding of the molecular mechanisms of biological denitrification under the blending treatment of leachate and high-nitrate wastewater.

\section{Introduction}

In China, the increasing amounts of municipal solid waste (MSW) are putting tremendous pressure on the treatment of landfill leachates. According to the survey data from the Professional Committee of Urban Domestic Refuse Treatment of the China Association of Environmental Protection Industry, the amount of MSW disposed by the Chinese government exceeded 191.1 million tons in 2015 (ref. 1) and is expected to reach 266.8 million tons by $2025 .^{2}$ In China, more than $60 \%$ MSW is disposed of in sanitary landfills, which produce large amounts of landfill leachates (Fig. S1†). However, due to the complex structure and high cost of landfill leachates, the treatment capacity of mainstream advanced technologies such as nanofiltration, reverse osmosis, advanced oxidation, and

${ }^{a}$ School of Civil Engineering, Guangzhou University, 510006, Guangzhou, China ${ }^{b}$ Shenzhen Municipal Wastewater Treatment and Recycling Engineering Laboratory, Shenzhen Water (Group) Co. Ltd., 518031, Guangdong, China. E-mail: zhouxingyu2017@163.com

${ }^{c}$ School of Environment, Harbin Institute of Technology, 150090, Harbin, China

$\dagger$ Electronic supplementary information (ESI) available. See DOI: 10.1039/c9ra07966a activated carbon adsorption are unable to keep pace with the generation rate of landfill leachates, which places substantial pressure on sanitary landfills for follow-up treatments. Therefore, it is imperative to find a reasonable strategy to treat landfill leachate.

As a cost-effective potential carbon source, blending landfill leachate with domestic sewage for treatment has become a popular research topic. Organic carbon concentration in raw wastewater of most municipal wastewater treatment plants (WWTPs) is very low, ${ }^{\mathbf{3}, 4}$ but the denitrification process needs a large number of carbon sources for consumption as electron donors. Therefore, to prevent incomplete denitrification and nitrite nitrogen accumulation caused by insufficient carbon sources, supplementary carbon sources such as methanol, acetic acid, or glucose need to be added to the denitrification tank to ensure that the total nitrogen content in the effluent meets the emission standards. ${ }^{5,6}$ Moreover, rapidly biodegradable forms of organic matter, such as short-chain fatty acids (SCFAs) and volatile fatty acids (VFAs), contained in landfill leachates can provide a carbon source that can be easily assimilated by microorganisms during the denitrification process. Consequently, the combined treatment of landfill leachates and domestic sewage in WWTPs has been extensively 
studied around the world..$^{7-10} \mathrm{Yu}$ et al. designed an anaerobicanoxic-oxic $\left(\mathrm{A}^{2} / \mathrm{O}\right)$ bioreactor system to conduct a field test on the combined treatment of domestic wastewater with landfill leachates in the Datangsha WWTP (Guangzhou, China); they found that the removal rates of chemical oxygen demand (COD), ammonia nitrogen $\left(\mathrm{NH}_{4}{ }^{+} \mathrm{N}\right)$, and total nitrogen (TN) were $82.65 \%, 92.69 \%$, and $57.10 \%$, respectively, at the optimal volume ratio of $0.2 \% .{ }^{11}$ Ferraz et al. studied the optimal mixing ratio for the cotreatment of landfill leachate and domestic sewage in a Brazilian WWTP using a pilot-scale submerged aerobic biofilter $(\mathrm{SAB})$. The results showed that the removal rates of biological oxygen demand (BOD), COD, and dissolved organic carbon (DOC) were $98 \%, 80 \%$, and $80 \%$, respectively, when the leachate volume ratio was $2 \% .^{12}$ Landfill leachate cotreatment with sanitary wastewater was investigated at the bench scale in an upflow anaerobic sludge blanket (UASB), and the COD removal rate was greater than $70 \%$ for leachate volume ratios of up to $5 \% .^{13} \mathrm{~A}$ combined system of a long-term lab-scale reactor was used for a more comprehensive cotreatment of landfill leachate and municipal sewage at volumetric ratios of $1 \%, 3 \%$, and $5 \%$, and the excess sludge could be reduced by $20-$ $48 \%$, resulting in no inhibitory effect on the denitrification process. ${ }^{14}$ Three Irish WWTPs were selected for field testing by Brennan et al., who deemed that the coprocessing of landfill leachate with municipal sewage may be the most sustainable leachate treatment solution that is currently available. ${ }^{15}$ However, research concerning cotreatment with landfill leachate has been limited to municipal domestic sewage, and reports regarding the cotreatment of landfill leachate and highnitrate wastewater are rare.

Wastewater containing high nitrate concentrations is widely derived from various types of industrial applications, such as fertilizer production, ${ }^{\mathbf{1 6}}$ stainless steel manufacturing and fish canning: ${ }^{17}$ cellophane finishing, ${ }^{18}$ wet lime-gypsum desulfurization production, ${ }^{19}$ nuclear applications, ${ }^{20}$ and ion exchange processes. ${ }^{21}$ When compared with domestic sewage treatment, the denitrification process consumes more carbon sources when a biological process that can completely remove nitrogen is used to treat such high-nitrate wastewater. Fernández-Nava et $a{ }^{22}$ studied denitrification in a sequencing batch reactor (SBR) fed with nitrate $\left(2500 \mathrm{mg} \mathrm{L}^{-1}\right)$ using wastewater from a candy factory, residue from a soft drink factory, and residue from a dairy plant as the organic carbon sources. Nevertheless, it is still unclear whether landfill leachate can be used as an alternative carbon source for the treatment of high-nitrate wastewater or not.

The current study aimed to evaluate the behavior of landfill leachate when cotreated with high-nitrate wastewater in a labscale SBR. To better assess the organic matter and nitrogen removal characteristics, the denitrification rates of activated sludge in the treatment of high-nitrate nitrogen at different landfill leachate volume ratios were compared. The effects of landfill leachate on the denitrification efficiency of activated sludge systems were revealed from the microbial structure and denitrification functional genes by combining 16S rDNA sequencing and quantitative real-time PCR (q-PCR) analyses. A new resource utilization model of landfill leachate was comprehensively explored, which could provide a technical reference for the selection of economical and efficient additional carbon sources for the treatment of high-nitrate wastewater.

\section{Materials and methods}

\subsection{Experimental materials}

2.1.1 Experimental apparatus setup and operation. Two lab-scale plexiglass cylindrical SBR bioreactors (R0 and R1) were designed with an inner diameter of $150 \mathrm{~mm}$, height of $600 \mathrm{~mm}$, and effective volume of $10 \mathrm{~L}$ (Fig. 1). These two SBRs were operated under intermittent loading with a hydraulic residence time (HRT) of $8 \mathrm{~h}$, including a stirring time of 3-5 h, settling time of $0.5 \mathrm{~h}$, unloading period of $0.25 \mathrm{~h}$, and loading period of $0.25 \mathrm{~h}$.

2.1.2 Characteristics and pretreatment of landfill leachates. The landfill leachate used as a feed in the experiments was collected from the Xiaping Municipal Sanitary Landfill, Shenzhen, China. Before being mixed with high-nitrate wastewater in the SBR bioreactor, the leachate was pretreated by ammonia stripping and anaerobic fermentation according to the procedures described by El-Gohary and Kamel. ${ }^{23}$ Ammonia stripping was achieved by aeration of the landfill leachate for $6 \mathrm{~h}$ with compressed air at a flow rate of $3 \mathrm{~L} \mathrm{~min}^{-1}$ and $\mathrm{pH}$ value of 8.511. A sealed glass anaerobic reactor with an effective volume of $5 \mathrm{~L}$ and inoculated with activated sludge from the primary sedimentation tank of a sewage treatment plant (Shenzhen, China) was used to ferment the landfill leachate. The leachate treated by ammonia stripping was injected into the anaerobic fermentation tank. The leachate was fermented for $24 \mathrm{~h}$ at $25{ }^{\circ} \mathrm{C}$ after anaerobic conditions were established by adding nitrogen for 5 min. After pretreatment, $\mathrm{NH}_{4}{ }^{+}-\mathrm{N}$, suspended solids (SS), and other pollutants in the landfill leachate were effectively degraded, and the biodegradability was improved (Table S1†).

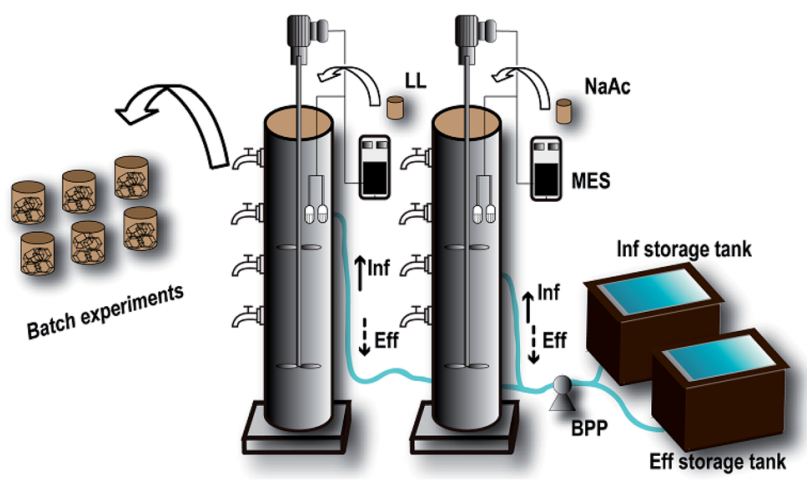

Fig. 1 Schematic diagram of the SBRs. The two SBRs were equipped with a stirrer, dissolved oxygen meter, and $\mathrm{pH}$ and temperature meters controlled by a multifunctional electronic switch (MES). The influent (Inf) and effluent (Eff) of the reactors were controlled by a bidirectional-flow peristaltic pump (BPP). At the domestication stage, the landfill leachate (LL) was added to the experimental group (R1), while sodium acetate ( $\mathrm{NaAc}$ ) was added to the control group (RO). The domesticated sludge obtained from the R1 reactor was used to perform the batch experiments. 
2.1.3 Synthetic high-nitrate wastewater. In this experiment, the SBR bioreactor was fed with synthetic high-nitrate wastewater (Table $\mathrm{S} 2 \dagger$ ) with potassium nitrate as a nitrogen source and potassium dihydrogen phosphate as a phosphorus source at a N/P ratio of 5 . Trace elements were also added as nutrients in the form of a preparatory solution at a ratio of $1 / 1000(\mathrm{v} / \mathrm{v})$. To maintain anoxic conditions, the dissolved oxygen concentration in the two reactors was controlled within $0.4 \mathrm{mg} \mathrm{L}^{-1}$. The $\mathrm{pH}$ of the mixture was adjusted to $7.5 \pm 0.2$ by adding hydrochloric acid, and the reaction temperature was maintained at room temperature, i.e., $23-27^{\circ} \mathrm{C}$.

2.1.4 Inocula and microorganisms. The two SBRs were inoculated with the same amounts of activated sludge (mixed liquor suspended solids (MLSS)) of approximately $6000 \mathrm{mg} \mathrm{L}{ }^{-1}$; the sludge volume after $30 \mathrm{~min}\left(\mathrm{SV}_{30}\right)$ was approximately $30 \%$ that of the anoxic section of the modified University of Cape Town (MUCT) biochemical unit in a WWTP in South China.

\subsection{Experimental procedures}

The experiment was divided into domestication phases, denitrification rate contrast phases, and optimal volume ratio research phases. Prior to introducing the landfill leachate into the SBR, the activated sludge underwent a 6week acclimation period (85 operating days with $8 \mathrm{~h}$ anoxic reaction cycles). During the startup, the reactor was fed with synthetic high-nitrate wastewater at increasing concentrations step by step in the range of $50-500 \mathrm{mg} \mathrm{L}^{-1}$ with NaAc as the carbon source and $\mathrm{COD} / \mathrm{NO}_{3}{ }^{-}-\mathrm{N}$ ratio $(\mathrm{C} / \mathrm{N}$ ratio) of 5.0. After this domestication stage, R0 was used as the control system and operated in the original acclimation mode, while R1 was used as the experimental system and operated to cotreat the landfill leachate and high-nitrate wastewater (NaAc was partially replaced by the landfill leachate); the denitrification rates in the two bioreactors were then compared. To explore the optimum mixing ratio of the landfill leachate, batch experiments with $\mathrm{C} / \mathrm{N}$ ratios of 2.5 , $3.2,4.5,4.9,5.6$, and 6.1 were performed. The volume ratios of the landfill leachate in each batch of the 6 reactors were $0 \%, 2.5 \%, 5 \%, 7.5 \%, 10 \%$, and $20 \%$, and the amount of NaAc added (Table 1) was correspondingly decreased.

Table 1 NaAc dosage at different volume ratios of landfill leachate in batch experiments

\begin{tabular}{|c|c|c|c|c|c|c|}
\hline \multirow[b]{2}{*}{$\begin{array}{l}\text { Volume ratio of } \\
\text { landfill leachate (\%) }\end{array}$} & \multicolumn{6}{|c|}{$\underline{\text { Sodium acetate dosage }\left(\mathrm{g} \mathrm{L}^{-1}\right)}$} \\
\hline & $\begin{array}{l}\mathrm{C} / \mathrm{N}= \\
2.5\end{array}$ & $\begin{array}{l}\mathrm{C} / \mathrm{N}= \\
3.2\end{array}$ & $\begin{array}{l}\mathrm{C} / \mathrm{N}= \\
4.5\end{array}$ & $\begin{array}{l}\mathrm{C} / \mathrm{N}= \\
5.0\end{array}$ & $\begin{array}{l}\mathrm{C} / \mathrm{N}= \\
5.6\end{array}$ & $\begin{array}{l}\mathrm{C} / \mathrm{N}= \\
6.1\end{array}$ \\
\hline 0 & 1.79 & 2.29 & 3.21 & 3.50 & 4.00 & 4.36 \\
\hline 2.5 & 1.65 & 2.15 & 3.07 & 3.36 & 3.86 & 4.22 \\
\hline 5.0 & 1.51 & 2.01 & 2.93 & 3.22 & 3.72 & 4.08 \\
\hline 7.5 & 1.37 & 1.87 & 2.79 & 3.08 & 3.58 & 3.94 \\
\hline 10.0 & 1.23 & 1.73 & 2.65 & 2.94 & 3.44 & 3.80 \\
\hline 20.0 & 1.09 & 1.59 & 2.51 & 2.80 & 3.30 & 3.66 \\
\hline
\end{tabular}

\subsection{Chemical analysis of wastewater samples and landfill} leachate

Samples $(10 \mathrm{~mL})$ were collected from a fixed sampling port and diluted a certain number of times, after which the supernatant was filtered through a $0.22 \mu \mathrm{m}$ filter membrane. SS, COD, BOD, $\mathrm{NO}_{2}{ }^{-}-\mathrm{N}$, and $\mathrm{NO}_{3}{ }^{-}-\mathrm{N}$ in the landfill leachate and bioreactor samples were measured according to the Standard Methods for the Examination of Water and Wastewater. ${ }^{24}$ The concentrations of heavy metals in the landfill leachate $(\mathrm{Cd}, \mathrm{Cr}, \mathrm{As}, \mathrm{Pb}, \mathrm{Hg}$, and Mo) were analyzed. Details of the above methods and instruments are listed in Table S3. $\dagger$ The concentration of dissolved oxygen (DO) and $\mathrm{pH}$ were measured using signal feedback DO and $\mathrm{pH}$ equipment (Hach, USA). The mixed liquid volatile suspended solids (VSS) content of the activated sludge samples was determined by the muffle furnace combustion gravimetric method, and the maximum specific denitrification rate was defined as the amount of nitrate removed per unit weight of VSS per unit time.

\subsection{DNA extraction and PCR}

To qualitatively analyze the denitrification function, genes in the two bioreactors and DNA in the sludge samples were extracted for performing the polymerase chain reaction (PCR) analysis. Sludge samples were centrifuged at a speed of 14000 $\times g$ for $5 \mathrm{~min}$ before supernatant removal. All the DNA was extracted from the concentrated sludge using a FastDNA soil kit (MP Biomedicals, USA), and the DNA concentration and purity were measured by a Nanodrop nd-1000 instrument (Nanodrop Technologies, USA). The nitrate reductase gene narG, nitrite reductase genes nirK and nirS, nitric oxide reductase gene nor $\mathrm{B}$, and nitrous oxide reductase gene nos $\mathrm{Z}$ were amplified using the PCR primers (as listed in Table $\mathrm{S} 4 \dagger$ ). The PCR system contained $10 \mu \mathrm{L}$ hot-start Premix Ex Taq $^{\mathrm{TM}}$ version (Tiangen Biotech, Beijing), $1 \mu \mathrm{L}$ upstream primer, $1 \mu \mathrm{L}$ downstream primer, $0.5 \mu \mathrm{L}$ DNA template, and $7.5 \mu \mathrm{L} \mathrm{ddH}_{2} \mathrm{O}$. The PCR products were detected by agarose gel electrophoresis at a mass concentration of $1.5 \%(\mathrm{w} / \mathrm{v})$ in $10 \times$ TAE buffer. The PCR was repeated three times for each sample, and sterile water was used as a negative control to check repeatability.

\subsection{MetaVx ${ }^{\mathrm{TM}}$ library construction and Illumina MiSeq sequencing}

In order to analyze the microbial communities in the two bioreactors, $15 \mathrm{~mL}$ of the mixture was taken from the bottom of the $\mathrm{R} 0$ and $\mathrm{R} 1$ reactors on the 0 th (inoculated sludge) and 65th (acclimated activated sludge) days of system operation, respectively, and the sludge samples were cryopreserved and sent to GENEWIZ (Suzhou, China) for 16S rRNA gene sequencing. The construction of a high-throughput sequencing library and sequencing based on the Illumina MiSeq platform were completed by GENEWIZ. A Qubit 2.0 fluorometer (Invitrogen, USA) was used to determine the concentration of DNA samples, and a sequencing library was constructed using the MetaVx $^{\mathrm{TM}}$ Library Construction Kit (GENEWIZ, USA). Using a 30-50 ng DNA sample as the template, two highly variable 
regions of prokaryotic 16S rDNA, namely, V3 and V4, were amplified by a series of PCR primers. The V3 and V4 regions were amplified using an upstream primer containing the "CCTACGGRRBGCASCAGKVRVGAAT" sequence and downstream primer containing the "GGACTACNVGGGTWTCTAATCC" sequence. In addition, a primer with an index connector was added to the end of the PCR product of 16S rDNA by PCR for NGS sequencing. The quality of the library was determined using an Agilent 2100 bioanalyzer (Agilent Technologies, USA), and the library concentrations were determined by a Qubit 2.0 fluorometer. After the DNA library was mixed, the Illumina MiSeq platform (San Diego, USA) was used for dualend sequencing, and the sequence information was read by the MiSeq control software (MCS).

\subsection{RNA extraction and q-PCR}

In order to further quantify the differences in the denitrifying functional genes for both the bioreactors, five target denitrifying functional genes were analyzed using q-PCR. The total RNA was extracted from activated sludge by using the TRIzol reagent (Invitrogen, Shanghai); further, cDNA was synthesized using a reverse transcription kit (Promega, Beijing). Here, q-PCR was performed using a SYBR green qPCR kit (Genestar, Beijing) and detected in a LightCycler 480 II system (Roche, Switzerland).

The q-PCR primers and amplification procedures for each gene are listed in Table $\mathrm{S} 4 . \dagger$

\subsection{Analytical methods}

The forward and reverse reads obtained by double-end sequencing were connected via two assemblies: filtering sequences containing $\mathrm{N}$ in the splicing result and retaining sequences with a sequence length greater than $200 \mathrm{bp}$. After mass filtration, the chimeric sequences were removed, and the resulting sequences were used for operational taxonomic unit (OTU) analysis. Sequence clustering was performed using VSEARCH (1.9.6) (sequence similarity was set to 97\%), and the aligned 16S rRNA reference database was Silva 132. Then, the Ribosomal Database Project (RDP) classifier based on the Bayesian algorithm was used to perform species taxonomic analysis on the OTU representative sequences. Further, the community composition of each sample was calculated at different species classification levels. The water quality indicator data were calculated using Excel 2007 and OriginPro 8.0 (OriginLab, Northampton) software.

\section{Results and discussion}

\subsection{Reactor performance}

The denitrification performance of the bioreactor is shown in Fig. 2. During the startup period (operating days: 0-45), the acclimation of the activated sludge with anhydrous NaAc as the carbon source improved its denitrification efficiency. The initial influent $\mathrm{NO}_{3}{ }^{-}-\mathrm{N}$ concentration was set at $50 \mathrm{mg} \mathrm{L}{ }^{-1}$ and then successively increased in 5 stages $(50 \rightarrow 100 \rightarrow 200 \rightarrow 300 \rightarrow$ $400 \rightarrow 500 \mathrm{mg} \mathrm{L}^{-1}$ ). The concentration level was raised when the nitrate removal rate reached $80 \%$. When the final concentration was increased to approximately $500 \mathrm{mg} \mathrm{L}^{-1}$, the removal rate remained above $90 \%$, and the effect remained stable for one week; at this point, the reactors were considered to be successfully started. After this acclimation stage, different volume ratios of landfill leachates were coprocessed with highnitrate wastewater. Landfill leachates were added to the R1 system at volume ratios of $20 \%, 10 \%$, and $5 \%$ from the 46 th, 61st, and 71st operating days, respectively. The removal rate of nitrate nitrogen and COD sharply decreased (average rates: $78.8 \%$ and $55 \%$, respectively) when the volume ratio was more than $10 \%$, while the average removal rate of COD increased to $68.2 \%$ and the denitrification efficiency of the reactor could be restored to its original level after 3 operating cycles when the volume ratio was less than $10 \%$. After acclimatization for 39 operating days $(\sim 46-85)$, the nitrate removal rate gradually increased to $98 \pm 1 \%$. The denitrifying bacteria were effectively adapted to the high concentration of $\mathrm{NO}_{3}{ }^{-}-\mathrm{N}$, which met the requirements for subsequent batch experiments to study the denitrification efficiency when landfill leachate was added as the carbon source under high load conditions.

\subsection{Effect of landfill leachate addition on denitrification}

$\mathrm{NaAc}$ was used as the carbon source in R0, and 10\% landfill leachate in R1 was mixed with high-concentration nitrate nitrogen wastewater. The $\mathrm{C} / \mathrm{N}$ ratio of each reactor was controlled at 5.0 in order to compare the denitrification rates in a typical cycle (Fig. 3) with sufficient electron donors. It took approximately $6 \mathrm{~h}$ for the R0 system to remove nitrate nitrogen almost completely (the effluent concentration was lower than the detection limit); the denitrification rate was $32.32 \mathrm{mg} \mathrm{NO}_{3}{ }^{-}$$\mathrm{N}(\mathrm{gVSS} \mathrm{h})^{-1}$, while the denitrification rate of the R1 system was $58.05 \mathrm{mg} \mathrm{NO}_{3}{ }^{-}-\mathrm{N}(\mathrm{gVSS} \mathrm{h})^{-1}$, which was 1.79 times higher than that of R0. This difference was mainly due to the diversity of COD sources in the landfill leachate. When compared with the single carbon source for R0, the mixed carbon sources for R1 facilitate accelerating the denitrification process of SBR, thereby improving the denitrification rate. ${ }^{25,26}$ Elefsiniotis ${ }^{27}$ and Wareham $^{28}$ suggested that when there are many carbon sources in a system, microorganisms can use many kinds of electron donors at the same time. It can be inferred that there was no zero-order reaction in the $\mathrm{R} 1$ system, but there was a coupling reaction involving multiple carbon sources; therefore, the denitrification rate was faster than that in R0, which had only one carbon source. In addition, leachates rich in $\mathrm{Ca}$ and $\mathrm{Mg}$ facilitate the rapid growth of biomass. Fernández-Nava et al. ${ }^{29}$ reported that increasing the calcium concentration from 50 to $150 \mathrm{mg} \mathrm{Ca}{ }^{2+} \mathrm{L}^{-1}$ yielded a 1.4 -fold increase in the denitrifying microorganism growth rate.

\subsection{Determination of optimum volume ratio of landfill leachate}

To investigate the removal of carbon and nitrogen at different volume ratios of landfill leachates, batch experiments were performed. Fig. 4A and B show that the denitrification rate was inversely proportional to the volume ratio of landfill leachate when the $\mathrm{C} / \mathrm{N}$ ratios were equal to 2.5 and 3.2. This relationship 


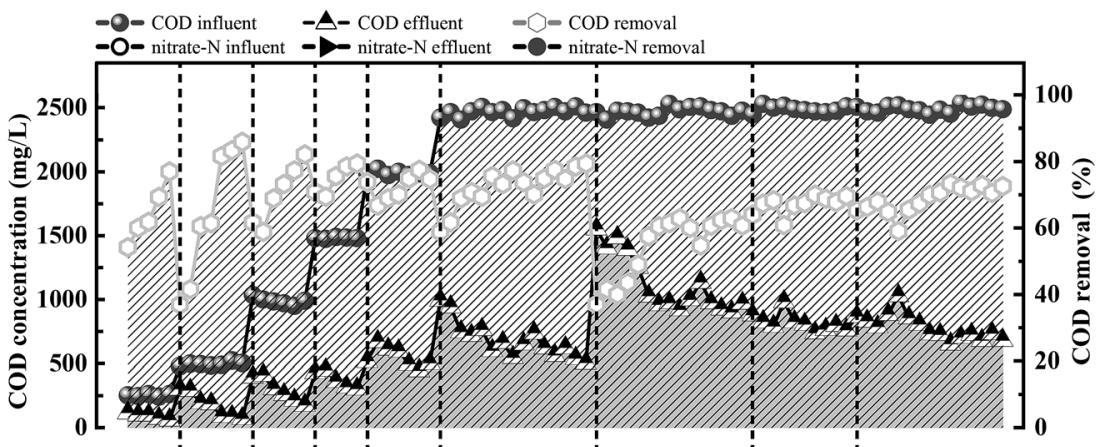

$\begin{array}{l:c:c:c:c:c}50 & 100 & 200 & 300 & 400 & 500\end{array}$

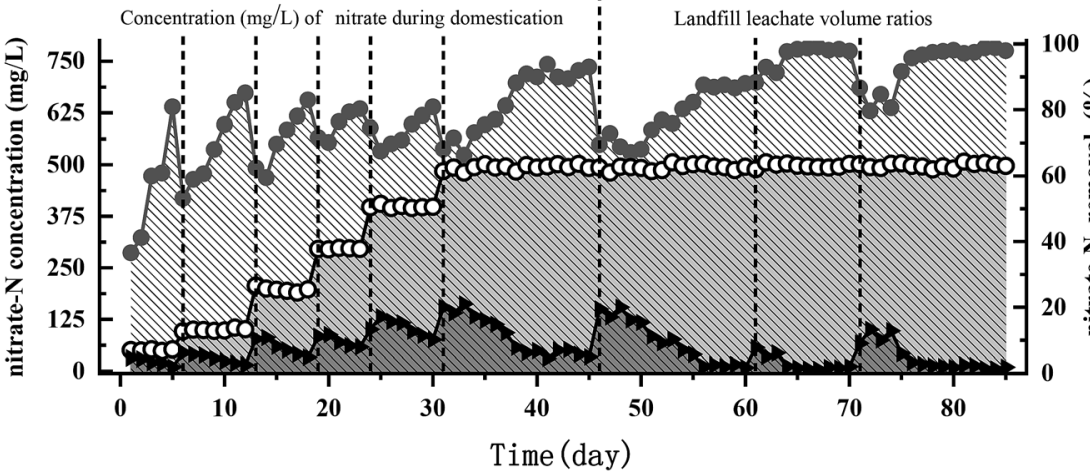

Fig. 2 Concentration and removal evolution of nitrate-N and COD in the SBR fed with different volume ratios of landfill leachates.

was due to the high proportion of macromolecule organic matter at a low carbon ratio. With increased leachate addition, the relative content of macromolecular organic matter exceeded the degradation capability for specific organic matter macromolecules. As a result, the electron donors could not completely reduce the high nitrate concentration in a given cycle, which decreased the reduction amount of nitrate nitrogen per unit time. When the landfill leachate volume ratio was less than $7.5 \%$, the denitrification rate accelerated with the increased addition amount at $\mathrm{C} / \mathrm{N}$ ratios of 4.5 and 5.0 (Fig. $4 \mathrm{C}$ and $\mathrm{D}$ ), and the maximum values were 61.03 and $62.28 \mathrm{mg} \mathrm{NO}_{3}{ }^{-} \mathrm{N}$ (gVSS $\mathrm{h})^{-1}$, respectively. When the addition ratio was more than $7.5 \%$, the denitrification rate decreased with increasing addition amount and reached the lowest value when the addition ratio was $20 \%$, resulting in values of 45.82 and $32.71 \mathrm{mg} \mathrm{NO}_{3}{ }^{-} \mathrm{N}$ $(\mathrm{gVSS} \mathrm{h})^{-1}$, respectively. This result could be attributed to the balance between the relative content of small-molecule carbon sources and complex carbon sources in the system, as well as the demand of different bacteria for various carbon sources under these conditions. Synergy between the microorganisms accelerates the reduction of nitrate nitrogen. In contrast, from Fig. $4 \mathrm{E}$ and $\mathrm{F}$, it is evident that the denitrification rate at $\mathrm{C} / \mathrm{N}$ ratios of 5.6 and 6.1 decreased with increasing landfill leachate volume fraction, which is related to the toxicity of
(A)

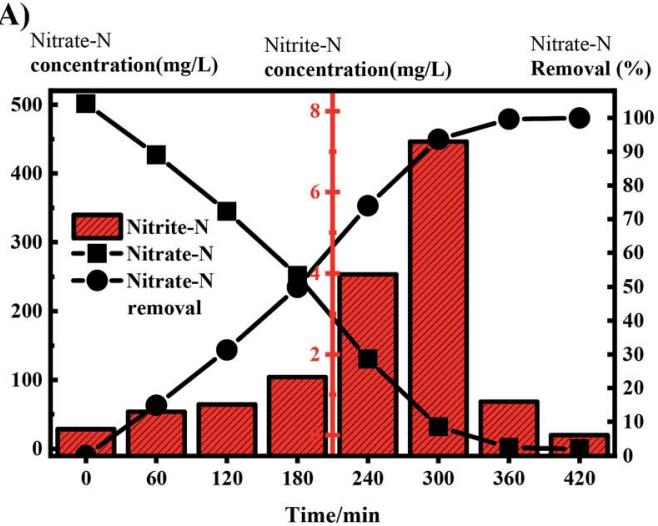

(B)

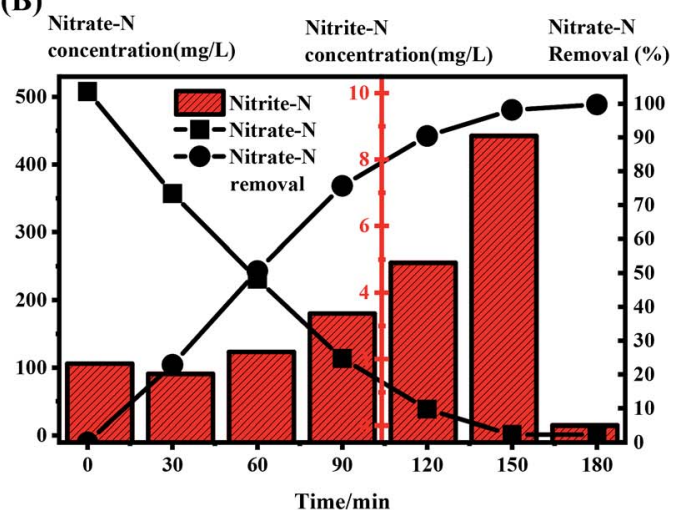

Fig. 3 Concentration evolution of nitrate- $\mathrm{N}$ and nitrite-N in a typical cycle at a C/N ratio of 5.0. (A) RO (no landfill leachate); (B) R1 (landfill leachate cotreatment). 

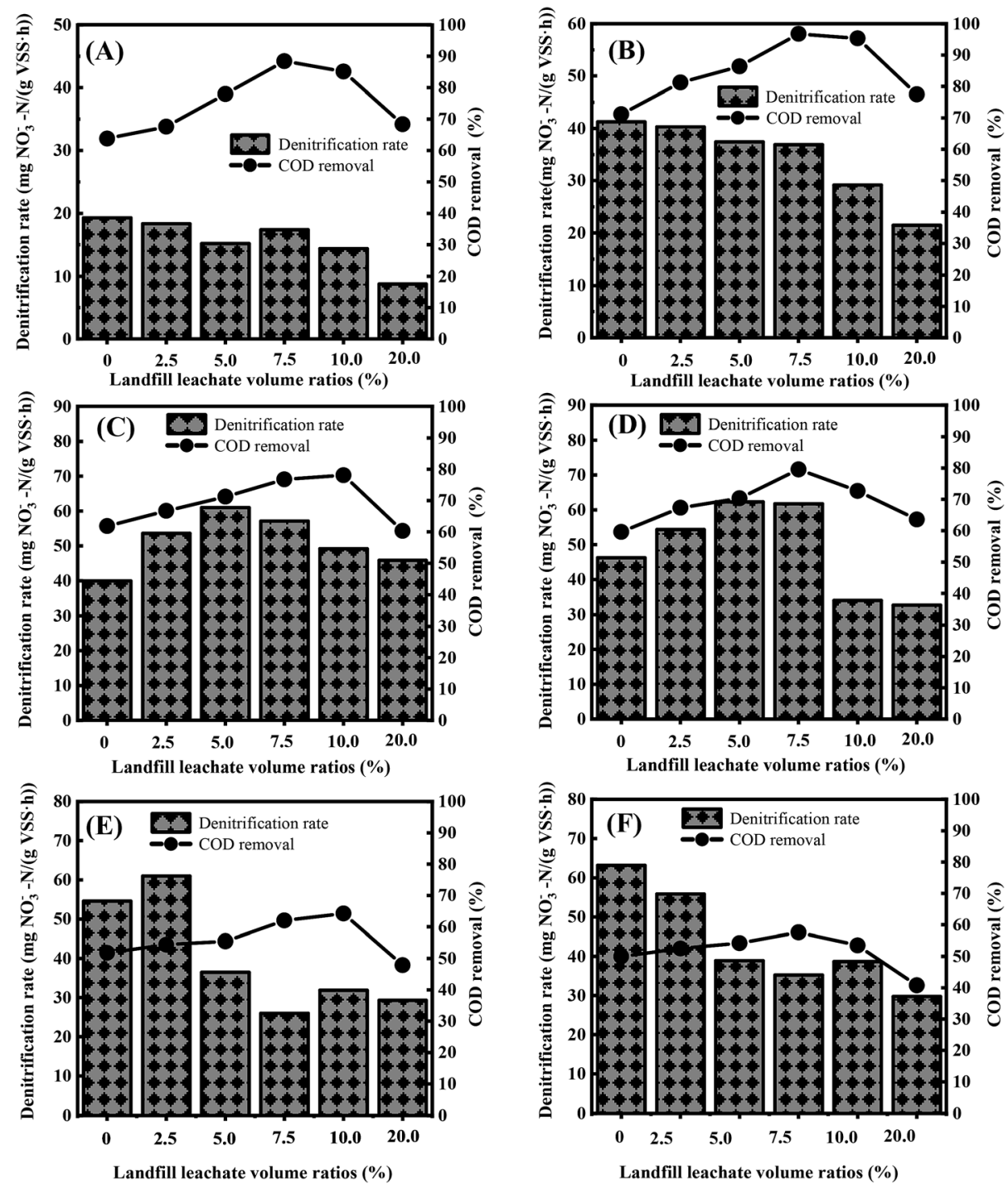

Fig. 4 COD removal and maximum specific denitrification rate at different $\mathrm{C} / \mathrm{N}$ ratios and landfill leachate volume ratios. $(\mathrm{A}) \mathrm{C} / \mathrm{N}$ ratio $=2.5 ;(\mathrm{B})$ $\mathrm{C} / \mathrm{N}$ ratio $=3.2 ;(\mathrm{C}) \mathrm{C} / \mathrm{N}$ ratio $=4.5 ;(\mathrm{D}) \mathrm{C} / \mathrm{N}$ ratio $=5.0 ;(\mathrm{E}) \mathrm{C} / \mathrm{N}$ ratio $=5.6 ;(\mathrm{F}) \mathrm{C} / \mathrm{N}$ ratio $=6.1$.

higher concentrations of free ammonia toward microorganisms $^{30-32}$ and is probably due to the cometabolism in the R1 system. Under the cometabolism mechanism, a high mass concentration ratio of the growth matrix to nongrowth matrix can exert competitive inhibition on the production of key enzymes..$^{33}$ In the R1 system, NaAc and nitrate acted as a part of the growth matrix, and complex organic matter (humic acid, $e t c$.) in the landfill leachate acted as a nongrowth matrix; when the $\mathrm{C} / \mathrm{N}$ ratio was 5.6 and 6.1, the dosage of NaAc was very high; therefore, it can be assumed that the mass concentration ratio of the growth matrix to the nongrowth matrix exceeded the demand range for cometabolism. ${ }^{34}$

In addition, converting the landfill leachate content into COD concentration reveals that the corresponding COD proportion was $4.10-13.5 \%$ when the landfill leachate volume fraction was $2.5-7.5 \%$ and the $\mathrm{C} / \mathrm{N}$ ratio was $3.2-5.0$. Landfill leachate COD ratios in the range of $4.10-13.5 \%$ promoted the reduction rate of nitrate nitrogen. As shown in Fig. 4C-F, when
$\mathrm{C} / \mathrm{N}$ was 4.5-6.1, the COD removal rate improved with increased landfill leachate addition, which indicates that the cotreatment of landfill leachate can promote the utilization of NaAc and reduce the dosage of NaAc. However, for $\mathrm{C} / \mathrm{N}=5.6$ and 6.1, the COD removal rates were less than $64.96 \%$, while for $\mathrm{C} / \mathrm{N}=3.2$, 4.5 , and 5.0, the COD removal rates reached $96.77 \%, 84.38 \%$, and $82.67 \%$, respectively. Therefore, considering both COD utilization and denitrification rate, it was suggested that the volume fraction of landfill leachate should be controlled at 2.57.5\% (COD concentration: $4.10-13.5 \%$ ) under the conditions of $\mathrm{C} / \mathrm{N}$ of 3.2-5.0, which accounts for both COD removal rate and denitrification rate.

\subsection{Molecular biological analysis}

3.4.1 Effects of landfill leachate addition on microbial community structure and relative abundance. The microbial community dynamics and characteristics (before and after 
adding landfill leachates) were evaluated by using highthroughput sequencing analysis. The bacterial community richness in the inoculated sludge was significantly reduced, which indicated that the dominant bacteria had been screened after domestication with NaAc and landfill leachate (Fig. 5 and $\mathrm{S} 2 \dagger)$. As shown in Fig. 5A, the three dominant bacteria with relative abundances greater than 1\% in R0 were Gammaproteobacteria (72.78\%), Alphaproteobacteria (20.98\%), and Bacteroidia $(4.77 \%)$, accounting for $98.53 \%$ of the total content. These results are highly similar to the microbial communities cultivated with NaAc. ${ }^{35-37}$ The four dominant bacteria with relative abundances greater than 1\% in R1 were Gammaproteobacteria (75.34\%), Alphaproteobacteria (14.57\%), Bacteroidia (4.73\%), and Clostridia $(3.51 \%)$. Cotreatment with landfill leachate increased the relative abundance of Gammaproteobacteria and Clostridia at the class level, while the abundance of Alphaproteobacteria and Bacteroidia was reduced.

At the order level (Fig. 5B), the five dominant bacteria in R0 were Pseudomonadales (54.75\%), Betaproteobacteriales (17.97\%), Micavibrionales (18.72\%), Bacteroidales (3.09\%), and Rhizobiales (1.91\%), accounting for $96.44 \%$ of the total content. The six dominant bacteria in R1 were Pseudomonadales $(60.08 \%)$, Betaproteobacteriales (15.2\%), Micavibrionales (11.05\%), Bacteroidales $(4.33 \%)$, Rhizobiales (2.93\%), and Clostridiales $(3.51 \%)$, accounting for $97.1 \%$ of the total content. These results indicated that adding landfill leachate not only increased the number of dominant functional bacteria at the order level but also stimulated the growth of Pseudomonadales and Clostridiales to change the community structure. The main families in R0 and R1 included Pseudomonadaceae, Rhodocyclaceae, Stappiaceae, Dysgonomonadaceae, and Rikenellaceae, with relative abundances of $54.63 \%, 18.13 \%, 1.91 \%, 1.59 \%$, and $1.49 \%$ in R0, respectively, and $60.08 \%, 15.24 \%, 2.93 \%, 2.44 \%$ and $1.89 \%$ in $\mathrm{R} 1$, respectively (Fig. $5 \mathrm{C}$ ). It is noteworthy that Clostridiaceae_2 increased from $0.05 \%$ to $2.33 \%$ (R1). At the genus level (Fig. 5D), 28 genera were detected in IS, while 17 genera were detected in R0 and R1, out of which Pseudomonas, Thauera, Pannonibacter, and Proteiniphilum were the dominant genera in the two reactors, with relative abundances of $44.75 \%, 20.49 \%$, $1.91 \%$, and $1.59 \%$ in $\mathrm{R} 0$, respectively, and $50.08 \%, 30.59 \%$, $2.93 \%$, and $2.44 \%$, in R1, respectively. These four denitrifying bacteria were enhanced and enriched in R1, while Pseudomonas, Thauera, and Pannonibacter had good denitrification characteristics..$^{38-40}$ The capability of the Pseudomonas aeruginosa PCN2 strain for nitrate reduction was confirmed by the PCR analyses of the ChrR, napA, nirS, cnorB and nos $\mathrm{Z}$ genes. ${ }^{41}$ In addition, Gram-negative bacillus Thauera sp. K11 was previously isolated from petrochemical wastewater by Qiao et al., ${ }^{42}$ who found that the bacteria could denitrify by using more than 10 phenolic derivatives as electron donors. Furthermore, the abundance of Anoxynatronum in R1 was $1.85 \%$, which was 46.25 -fold higher than that in R0 (only $0.04 \%$ ), indicating that landfill leachate was beneficial to the growth of Anoxynatronum. Garnova et al. ${ }^{\mathbf{4 3}}$ isolated an alkalophilic anaerobic bacterium, namely,
(A)

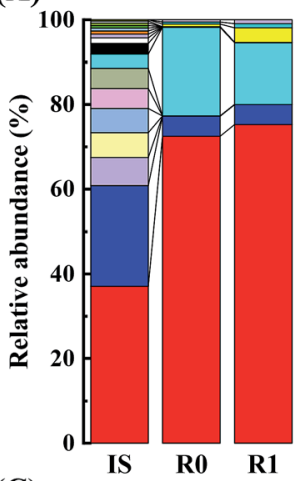

(C)

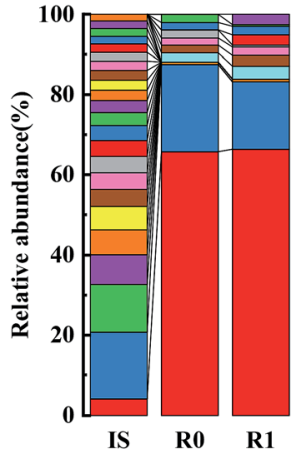

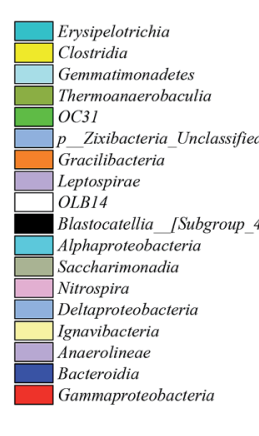

(B)

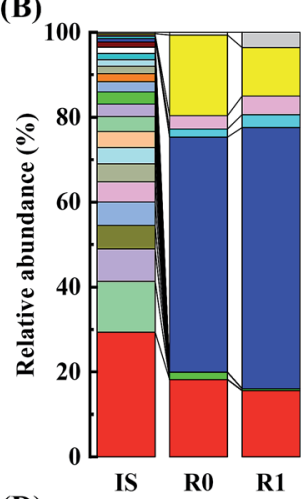

(D)

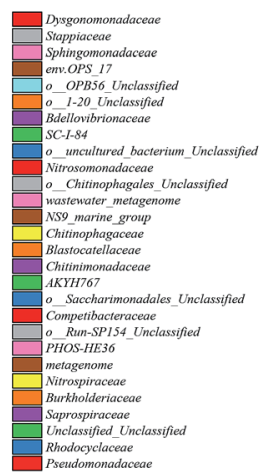

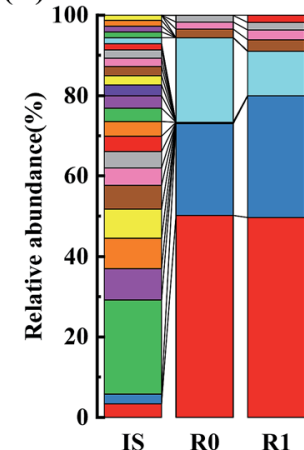
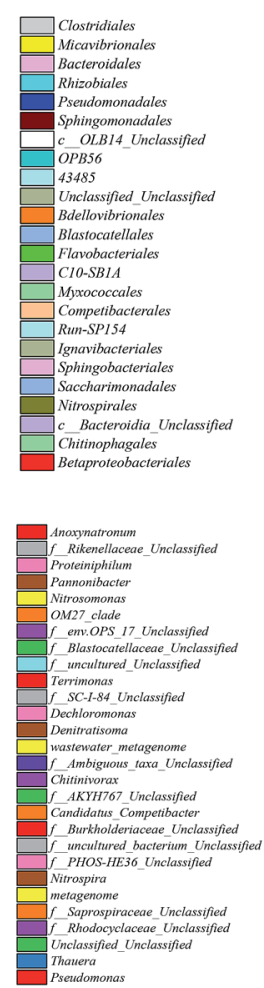

Fig. 5 Taxonomic classification of the bacterial communities at the (A) class level, (B) order level, (C) family level, and (D) genus level. IS: inoculated sludge; R0: activated sludge sample collected from R0 on the 65th day; R1: activated sludge sample collected from R1 on the 65th day. 
Anoxynatronum, from Lake Baikal and found that it can use cellulose and other macromolecular organic matter as a carbon source to achieve denitrification and can decompose more complex compounds, which explains the increase in the COD removal rate in batch experiments as the amount of leachate addition increased.

3.4.2 Effects of landfill leachate addition on denitrification functional genes. The complete denitrification process consists of four steps, namely, $\mathrm{NO}_{3}{ }^{-} \rightarrow \mathrm{NO}_{2}{ }^{-} \rightarrow \mathrm{NO} \rightarrow \mathrm{N}_{2} \mathrm{O} \rightarrow \mathrm{N}_{2}$, which were catalyzed by nitrate reductase (NAR), nitrite reductase (NIR), nitric oxide reductase (NOR), and nitrous oxide reductase (NOS), respectively. The coding genes for these four functional proteins were nar, nir, nor, and nos, respectively.

The q-PCR results are shown in Fig. 6. Except for the NOSencoding gene nos $\mathrm{Z}$, the relative abundance of the narG, nirS, nirK, and norB genes increased by 4.98-, 3.69-, 10.80-, and 2.38folds, respectively, in R1, indicating that the addition of landfill leachate can increase the relative abundance of the denitrification functional genes. The nir gene consisted of the coppercontaining nitrite reductase (Cu-NIR) coding gene nirK and heme-containing nitrite reductase (cd1-NIR) coding gene nirS. The abundant copper ions in the landfill leachate provide abundant substrate binding sites for type II copper of the copper-NIR monomer, thereby enhancing the relative abundance of nirK. Here, cd1-NIR is a homodimeric bifunctional enzyme that acts as a catalyst with azurin, pseudoazurin, or cytochrome c551 as electron donors; therefore, it can be speculated that landfill leachates provide the required electron donors to increase the relative expression of nirK. In addition, NAR activity can be enhanced by adding appropriate concentrations of $\mathrm{Fe}(\mathrm{III})$ and $\mathrm{Mo}(\mathrm{VI}),{ }^{44}$ and the presence of $\mathrm{Fe}(\mathrm{II})$ can increase the copy numbers of nirS and nos $\mathrm{Z}$ to facilitate $\mathrm{NO}_{2}{ }^{-}$ reduction and $\mathrm{N}_{2} \mathrm{O}$ formation. ${ }^{45}$ The results of the relative quantitative analysis of functional genes obtained by q-PCR help elucidate the difference in the denitrification efficiencies between the two reactors and enable the analysis of the feasibility of the cotreatment of landfill leachate with high-nitrate wastewater from the perspective of functional genes.

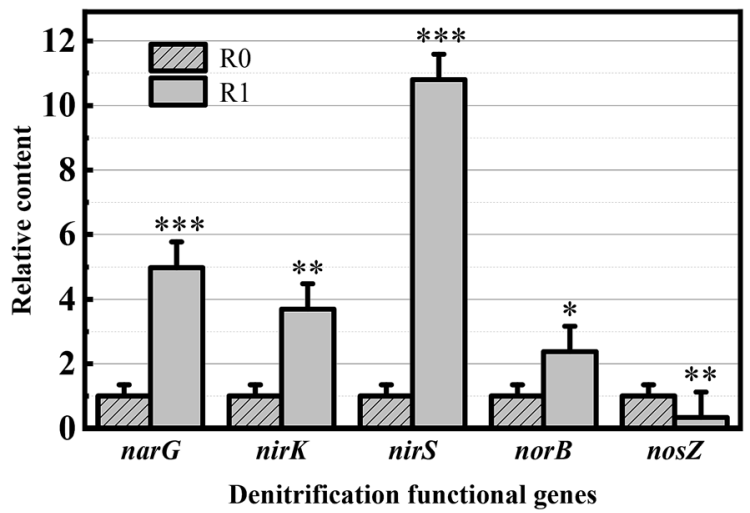

Fig. 6 Relative contents of denitrifying functional genes (narG, nirK, nirS, norB, and nosZ) in the R0 and R1 systems. *Significant at the 0.05 level in a two-tailed test. **Significant at the 0.01 level in a two-tailed test. ***Significant at the 0.001 level in a two-tailed test.

\section{Conclusions}

Landfill leachate and high-nitrate wastewater were cotreated to obtain efficient activated sludge for denitrification with a maximum denitrification rate of $62.28 \mathrm{mg} \mathrm{NO}_{3}{ }^{-}-\mathrm{N}(\mathrm{gVSS} \mathrm{h})^{-1}$. The cotreatment of landfill leachate and high-nitrate wastewater improved the utilization rate of NaAc (the COD removal rate reached 96\%). The addition of landfill leachate changed the relative abundances of dominant bacteria (Pseudomonas, Thauera, Pannonibacter, and Proteiniphilum increased, while Alphaproteobacteria and Bacteroidia decreased). After the cotreatment, the relative contents of the denitrification functional genes narG, nirK, nirS, and nor B increased by $398 \%$, $269 \%, 980 \%$, and $138 \%$, respectively.

\section{Conflicts of interest}

There are no conflicts to declare.

\section{Acknowledgements}

This work was supported by the China Post-doctoral Science Foundation (2019M653086), the Scientific Research Foundation of Shenzhen Water (Group) Co. Ltd. (20180004) and the Key Technology Assessment and Standardization of Urban Water Supply System Operation Management (2017ZX07501002). The authors would like to acknowledge the use of the the Light Cycler 480 II system at the School of Life Sciences, Sun Yat-Sen University.

\section{References}

1 CAEPI, Development Report on Treatment Industry of Urban Domestic Refuse in 2017, China Environmental Protection Industry, 2017, vol. 4, pp. 9-15.

2 H. Guo, J. M. Li, M. J. Qiu, J. L. Liu and W. C. Zhang, Multivariate linear regression prediction of domestic waste yield in China, Environ. \& Dev., 2018, 30(1), 61-63.

3 Y. Pan, B. Ni, P. L. Bond, L. Ye and Z. Yuan, Electron competition among nitrogen oxides reduction during methanol-utilizing denitrification in wastewater treatment, Water Res., 2013, 47, 3273-3281.

4 Y. Peng, Y. Ma and S. Wang, Denitrification potential enhancement by addition of external carbon sources in a pre-denitrification process, J. Environ. Sci., 2007, 19, 284289.

5 H. J. Hamlin, J. T. Michaels, C. M. Beaulaton, W. F. Graham, W. Dutt, P. Steinbach, T. M. Losordo, K. K. Schrader and K. L. Main, Comparing denitrification rates and carbon sources in commercial scale upflow denitrification biological filters in aquaculture, Aquacult. Eng., 2008, 38, 79-92.

6 P. J. Robinson and C. A. Woolhead, Post-translational membrane insertion of an endogenous YidC substrate, Biochim. Biophys. Acta, 2013, 1833(12), 2781-2788.

7 E. M. de Albuquerque, E. Pozzi, I. K. Sakamoto and P. Jurandyr, Treatability of landfill leachate combined with 
sanitary sewage in an activated sludge system, Journal of Water Process Engineering, 2018, 23, 119-128.

8 F. M. Ferraz, A. T. Bruni, J. Povinelli and E. M. Vieira, Leachate/domestic wastewater aerobic co-treatment: a pilot-scale study using multivariate analysis, J. Environ. Manage., 2016, 166, 414-419.

9 J. Kalka, Landfill Leachate Toxicity Removal in Combined Treatment with Municipal Wastewater, Sci. World J., 2012, 2012, 202897.

10 Z. L. Ye, X. Xie, L. Dai, Z. Wang, W. Wu, F. Zhao, X. Xie, S. Huang, M. Liu and S. Chen, Full-scale blending treatment of fresh MSWI leachate with municipal wastewater in a wastewater treatment plant, Waste Manag., 2014, 34(11), 2305-2311.

$11 \mathrm{~J}$. Yu, S. Zhou and W. Wang, Combined treatment of domestic wastewater with landfill leachate by using $\mathrm{A}^{2} / \mathrm{O}$ process, J. Hazard. Mater., 2010, 178(1-3), 81-88.

12 F. M. Ferraz, J. Povinelli, E. Pozzi, E. M. Vieira and J. C. Trofino, Co-treatment of landfill leachate and domestic wastewater using a submerged aerobic biofilter, J. Environ. Manage., 2014, 141, 9-15.

13 P. Torres, J. A. Rodríguez, L. E. Barba, L. F. Marmolejo and C. A. Pizarro, Combined treatment of leachate from sanitary landfill and municipal wastewater by UASB reactors, Water Sci. Technol., 2009, 60(2), 491-495.

14 M. Zheng, S. Li, Q. Dong, X. Huang and Y. Liu, Effect of blending landfill leachate with activated sludge on the domestic wastewater treatment process, Environ. Sci.: Water Res. Technol., 2019, 5, 268-276.

15 R. B. Brennan, E. Clifford, C. Devroedt, L. Morrison and M. G. Healy, Treatment of landfill leachate in municipal wastewater treatment plants and impacts on effluent ammonium concentrations, J. Environ. Manage., 2017, 188, 64-72.

16 T. Osaka, K. Shirotani, S. Yoshie and S. Tsuneda, Effects of carbon source on denitrification efficiency and microbial community structure in a saline wastewater treatment process, Water Res., 2008, 42(14), 3709-3718.

17 J. L. Campos, A. Mosquera-Corral, M. Sánchez, R. Méndez and J. M. Lema, Nitrification in saline wastewater with high ammonia concentration in an activated sludge unit, Water Res., 2002, 36(10), 2555-2560.

18 C. Glass and J. Silverstein, Denitrification of high-nitrate, high-salinity wastewater, Water Res., 1999, 33(1), 223-229.

19 K. Windey, B. I. De and W. Verstraete, Oxygen - limited autotrophic nitrification - denitrification (OLAND) in a rotating biological contactor treating high - salinity wastewater, Water Res., 2005, 39(18), 4512-4520.

20 C. Glass and J. Silverstein, Denitrification kinetics of high nitrate concentration water: $\mathrm{pH}$ effect on inhibition and nitrite accumulation, Water Res., 1998, 32(3), 831-839.

21 B. M. Peyton, M. R. Mormile and J. N. Petersen, Nitrate reduction with Halomonas campisalis: kinetics of denitrification at pH 9 and 12.5\% NaCl, Water Res., 2001, 35(17), 4237-4242.

22 Y. Fernández-Nava, E. Marañón, J. Soons and L. Castrillón, Denitrification of high nitrate concentration wastewater using alternative carbon sources, J. Hazard. Mater., 2010, 173(1-3), 682-688.

23 F. A. El-Gohary and G. Kamel, Characterization and biological treatment of pre-treated landfill leachate, Ecol. Eng., 2016, 94, 268-274.

24 APHA, Standard Methods for the Examination of Water and Wastewater, American Public Health Association/American Water Works Association/Water Environment Federation, Washington, DC, 22nd edn, 2012.

25 J. Sun, M. Guo, L. Zhao, Y. G. Gao, M. C. She and Z. lian, The effects of denitrification with sludge alkaline fermentation liquid and thermal hydrolysis liquid as carbon sources, RSC Adv., 2016, 6(76), 72333-72341.

26 F. Liu, Y. Tian, Y. Ding and Z. Li, The use of fermentation liquid of wastewater primary sedimentation sludge as supplemental carbon source for denitrification based on enhanced anaerobic fermentation, Bioresour. Technol., 2016, 219, 6-13.

27 P. Elefsiniotis and D. G. Wareham, Utilization patterns of volatile fatty acids in the denitrification reaction, Enzym. Microb. Technol., 2007, 41(1-2), 92-97.

28 P. Elefsiniotis, D. G. Wareham and M. O. Smith, Use of volatile fatty acids from an acid-phase digester for denitrification, J. Biotechnol., 2004, 114(3), 289-297.

29 Y. Fernández-Nava, E. Marañón, J. Soons and L. Castrillón, Denitrification of wastewater containing high nitrate and calcium concentrations, Bioresour. Technol., 2008, 99(17), 7976-7981.

30 F. Zhang, H. Yang, J. W. Wang, Z. Q. Liu and Q. K. Guan, Effect of free ammonia inhibition on NOB activity in high nitrifying performance of sludge, RSC Adv., 2018, 8(56), 31987-31995.

31 W. Qian, Y. Peng, X. Li, Q. Zhang and B. Ma, The inhibitory effects of free ammonia on ammonia oxidizing bacteria and nitrite oxidizing bacteria under anaerobic condition, Bioresour. Technol., 2017, 243, 1247-1250.

32 J. A. Torà, J. Lafuente, J. A. Baeza and J. Carrera, Combined effect of inorganic carbon limitation and inhibition by free ammonia and free nitrous acid on ammonia oxidizing bacteria, Bioresour. Technol., 2010, 101(15), 6051-6058.

33 M. Nsenga Kumwimba and F. Meng, Roles of ammoniaoxidizing bacteria in improving metabolism and cometabolism of trace organic chemicals in biological wastewater treatment processes: a review, Sci. Total Environ., 2019, 659, 419-441.

34 M. Xiao, X. Yin, H. Gai, H. Ma, Y. Qi, K. Li, X. Hua, M. Sun and $\mathrm{H}$. Song, Effect of hydroxypropyl- $\beta$-cyclodextrin on the cometabolism of phenol and phenanthrene by a novel Chryseobacterium sp, Bioresour. Technol., 2019, 273, 56-62.

35 S. L. S. Rollemberg, L. Q. de Oliveira, A. R. M. Barros, V. M. M. Melo, P. I. M. Firmino and A. B. Dos Santos, Effects of carbon source on the formation, stability, bioactivity and biodiversity of the aerobic granule sludge, Bioresour. Technol., 2019, 278, 195-204.

$36 \mathrm{Z}$. Xu, X. Dai and X. Chai, Effect of different carbon sources on denitrification performance, microbial community 
structure and denitrification genes, Sci. Total Environ., 2018, 634, 195-204.

37 L. Yan, M. Zhang, Y. Liu, C. Liu, Y. Zhang, S. Liu, L. Yu, G. Hao, Z. Chen and Y. Zhang, Enhanced nitrogen removal in an aerobic granular sequencing batch reactor under low DO concentration: role of extracellular polymeric substances and microbial community structure, Bioresour. Technol., 2019, 289, 121651.

38 H. Bai, S. Liao, A. Wang, J. Huang, W. Shu and J. Ye, Highefficiency inorganic nitrogen removal by newly isolated Pannonibacter phragmitetus B1, Bioresour. Technol., 2019, 271, 91-99.

39 Y. Mao, Y. Xia and T. Zhang, Characterization of Thaueradominated hydrogen-oxidizing autotrophic denitrifying microbial communities by using high-throughput sequencing, Bioresour. Technol., 2013, 128, 703-710.

40 L. Yang, X. H. Wang, S. Cui, Y. X. Ren, J. Yu, N. Chen, Q. Xiao, L. K. Guo and R. H. Wang, Simultaneous removal of nitrogen and phosphorous by heterotrophic nitrification-aerobic denitrification of a metal resistant bacterium Pseudomonas putida strain NP5, Bioresour. Technol., 2019, 285, 121360.
41 D. He, M. Zheng, T. Ma, C. Li and J. Ni, Interaction of Cr(VI) reduction and denitrification by strain Pseudomonas aeruginosa PCN-2 under aerobic conditions, Bioresour. Technol., 2015, 185, 346-352.

42 N. Qiao, L. Xi, J. Zhang, D. Liu, B. Ge and J. Liu, Thauera sinica sp. nov., a phenol derivative-degrading bacterium isolated from activated sludge, Antonie Leeuwenhoek, 2018, 111(6), 945-954.

43 E. S. Garnova, T. N. Zhilina, T. P. Tourova and A. M. Lysenko, Anoxynatronum sibiricum gen.nov., sp.nov. alkaliphilic saccharolytic anaerobe from cellulolytic community of Nizhnee Beloe (Transbaikal region), Extremophiles, 2003, $7(3), 213-220$.

44 P. Pintathong, D. J. Richardson, S. Spiro and W. Choorit, Influence of metal ions and organic carbons on denitrification activity of the halotolerant bacterium, Paracoccus pantotrophus P16 a strain from shrimp pond, Electron. J. Biotechnol., 2009, 12(2), 1-9.

$45 \mathrm{~S} . \mathrm{Li}, \mathrm{X} . \mathrm{M}$. Li and F. B. Li, Effect of Fe(II) on denitrification and associated functional microbial communities, China Environ. Sci., 2018, 38(1), 263-274. 